\title{
Food Balancing Assessment: A Three-Way Approach
}

\author{
Submitted 28/1 1/19, $1^{\text {st }}$ revision 20/12/19, $2^{\text {nd }}$ revision 29/01/20 accepted 06/03/20
}

\section{Sergey Baskakov ${ }^{1}$, Evgeny Rudoy ${ }^{2}$, Igor Vorotnikov $^{3}$, Irina Sukhanova ${ }^{4}$ Marina Ivanovna Glukhova ${ }^{5}$}

\begin{abstract}
:
Purpose: The aim of this article is the improvement of the theoretical bases and the development of a scientifically grounded approach balancing the food supply from the economic and the practical application for a complex social and economic assessment of development of the food sphere as a whole.

Design/Methodology/Approach: In the process of research the authors' approach was used to consider the balance of food supply from the position of three structural and consistently interrelated elements-phenomena, process and state. The authors' interpretation of each element is given, the method of their evaluation is developed, based on the structural division of indicators into balanced ones, exceeding the level of balance and being below the specified level. These indicators are differentiated into 7 functional groups (from the minimum to the maximum degree of balance).

Findings: The result is a comparative assessment of the level of balance of food supply in the UK, France, Czech Republic, Latvia and Russia and the definition on its basis of priority directions of development of agriculture in each of the allocated states.

Practical Implications: The results of the work can be used by governing bodies to make specific practical decisions in the food sector, and to adjust the directions of its development. Originality/Value: Materials of the article are original and have not been previously published. The calculations were based on official data from the European Statistical Agency, Eurostat and the Federal State Statistics Service of Russia, which indicates the reliability of the presented scientific materials.
\end{abstract}

Keywords: Food supply balance, balance indicators, Pareto optimality, imbalances.

JEL codes: D50, L66, Q18.

Paper type: Research article.

${ }^{1}$ Corresponding author, Novosibirsk State Agrarian University - Novosibirsk Russian

Federation, Assistant professor, Department of Economics, Romann1960@mail.ru

${ }^{2}$ Novosibirsk State Agrarian University - Novosibirsk Russian Federation, Rector, rector@nsau.edu.ru

${ }_{3}^{3}$ Saratov State Agrarian University named after N.I. Vavilov - Saratov Russian Federation, Vice-Rector for Research, nir@sgau.ru

${ }^{4}$ Saratov State Agrarian University named after N.I. Vavilov - Saratov Russian Federation, Head, Department of Agriculture Economics, suhanovaif@sgau.ru

${ }^{5}$ Ph.D., Associate Professor, Department of Economy and Management, Sechenov First Moscow State Medical University, Orcid: 0000-0002-7852-3093, miss4@yandex.ru 


\section{Introduction}

The problems of food supply for people and food provision with not expensive food products of a good quality are seen as a prior direction in national policy. This is explained by the fact that food supply has an impact on the population and the efficiency of all industries and the society. Regardless scientific and technological achievements, gene engineering, development of information, computer, medical and machine-building technologies, the nutrition needs are still the fundamental ones.

Due to this fact, the possible balance in food supply is gaining relevance and significance. This is explained by the fight against hunger and improvement of nutrition of poor people from the poorest countries of the world (Hopkins, 2009; Clapp, 2012), and by efficient distribution of domestic and export food flows in the most economically developed countries (Rask and Rask, 2011). These processes differ in terms of organizational and economic content, but in both of them agricultural producers focus on satisfying consumers' needs in agricultural products. This process requires specific measures for coordination of economic and social interests of the actors in the food market. Due to this fact, the balance of food supply can become an efficient criterion aimed at efficient development of agricultural producers when satisfying human needs in food products of good quality.

The scientific community has not yet come up with general terms and approaches that could define the mechanism for achieving food supply balance. The first group of researchers regard the balance of economic results of agricultural production and its environmental impact as a basic criterion of food balance (Cassman and Harwood, 1995; Crute, 2012). The second group of scientists refer to the balance of supply and demand at the food market (Vorob'ev, 2005; Brykin, 2011; Nadezhdina and Peshkova, 2014; Chen and Nie, 2016). The third group of researchers focus on comparison between production and consumption of agricultural products (Kostusenko, 2009; Silaeva et al., 2009; Shibajkin, 2009) while the fourth group of scientists consider the balance between the market and society as a prior development (Fraser and Lansink, 2017). The fifth group of scientists analyze the balance between food provision and population in respect to technological progress (Hossain, 2007). The balance of food supply is estimated from the logistic point of view (Vorotnikov et al., 2017), when prices correspond to the actual costs of food products (Sulejmanov and Nasrullaeva, 2012), the models of efficient land-use (Sali et al., 2016), possible approaching the criteria of balanced nutrition (Usenko, 2006; Shapkina, 2011), and food security explored from the point of view of government intervention and fair competition (Umali-Deininger and Deininger, 2001).

The authors highlight that general approaches to the food supply balance assume comparison of problematic criteria, their estimation and benchmarking (comparative analysis). All scientists have a common view that food problems should be solved on a regular basis. 
When analyzing the problem, the researchers should use a complex approach as all the scientific views suffer from biased benchmarking and comparative analysis. The scientists analyze conformity of certain economic parameters or group of parameters among each other not considering the components of the food supply balance. This approach does not reveal all features of food supply balance implementation.

The authors regard the nature of food supply balance as sustainable lifelong and progressive development of the food system when changes in parameters of this system correlate among each other and are of a proportional type. The main goal of the food supply balance is providing people with food products of good quality and range, which are sufficient for keeping them in a healthy and productive life. The components of this notion should be explored on a complex basis from 3 structural and related elements:

First, balance is seen as a phenomenon originating from economic reality and relating to efficient operation of food supply system.

Second, balance is a process aimed at eliminating great disparities and imbalance in food supply development.

Third, balance characterizes the state of food supply system and its ability to operate efficiently.

The authors note that consistent substantial and functional complication of this category when transferring from a phenomenon to a process and then to the state is logical, because each step highlights more complex mechanisms of its achievement. These mechanisms are based on different characteristics of equilibrium of the food supply system and the need to coordinate the increasing number of parameters among themselves.

\section{Methodology}

With regard to food supply balance as a phenomenon relates to achievement of equilibrium parameters of food production and consumption. The authors' point of view is based on significance of food products for human life, which is the main criterion of human life's activity. Conformation to the appropriate level of proportions when changing the indicators of food production and consumption requires coordination of economic and social interests of food market actors, which are the key elements of the internal content of the food sector.

Economic elements of food market (agricultural producers, processing enterprises and retail organizations) aim at profit maximizing by means of reducing costs and expanding the food market. The socially-oriented elements of the food market, seen as different groups of people, aiming at receiving sufficient food products and minimizing the costs for these products' purchase. On the one hand, we see a 
contradiction that must be solved by administration bodies. The measures at the food market are related among each other as they do not assume operation of one group of elements without the other one. The international and Russian experience show that food standards serve as qualitative characteristics of the food supply balance as a phenomenon. Achievement and implementation of these standards is an efficient criterion that characterizes its most efficient form. For instance, these are the rates of the consumer basket, and, in regards to Russia, these are food standards endorsed but still not implemented at the national level. Due to the data mentioned above, the "Pareto principle of optimality" when considering the balance of food supply as a phenomenon can be formulated as "food supply as a phenomenon of optimality in case when the change in the dynamics of food production does not reduce the established norms of human nutrition".

Thus, the authors render the phenomenon of food supply balance "as conformation and following to the endorsed food rates regardless the dynamics of agricultural production that is achieved by means of interest alignment among economicallyoriented and socially-oriented elements of the food system".

The final data to be compared in order to assess the food supply balance as a phenomenon $(B p h)$ are seen as a physical output indicator (Vpri) on the one side, and consumer basket rates (Ni) on the other side as in euqtion (1):

$$
B_{p h}=\frac{\sum V_{p r i}}{N_{i}} \times 100 \%
$$

Considering the food supply balance as a process, we proceed from the generally accepted concepts of the process approach. According to this approach, a process is a course, development of a certain phenomenon, a consistent and logical change of its states. Exploring this category, Repin and Eliferov (2008) point out that the process is a stable and task-oriented set of interrelated types of activity, which transforms "inputs" into "outputs" of value to the consumer according to a certain technology. This concept is characterized by instruments and methods that can be applied when carrying out interrelated actions and operations in order to obtain a predetermined product, result or service. Hammer adds effective character to the process and links it with various activities that use resources for producing a final product. Hammer underlines that the process approach can be the instrument, which can result in efficient administration at any organization or branch (Hammer, 2004).

This category can be structurally divided into 4 related stages: agricultural production, processing of the agricultural production and producing food products, their merchandising and consumption. The "inputs" in this process are all types of resources used by food supply entities in their activities, and the "outputs" are the amount of produced (appropriate range and good quality) and further consumed food products. 
Structural differentiation of food supply process into administration processes is realistic in case of complete administration at all stages, as each of the stages is implemented by different subjects: agricultural producers, processing enterprises, retailers and population. The subjects differ from each other in efficiency and balance assessment. These are different qualitative indicators that serve as the main direction of the process coordination.

The Pareto criterion of optimality for food balance as a process can be formulated as follows "Food supply as a process is efficient when changes in the dynamics of resource application at the stages do not reduce the amount, variety and quality of produced and consumed food products".

The analysis carried out formulates the notion of food supply balance as a process as proportional change in the dynamics of resources use at the stages of food supply to the amount, variety and quality of produced and consumed food products; this dynamic change is carried out by means of alignment of indicators of the food system. In this case food supply balance (Bpr) is determined by relation between total number of food products produced (Cost food) and price parameters of costs for production and processing of agricultural production taken by agricultural producers (Expenses) as in equation (2):

$$
B_{p r}=\frac{\sum C_{f_{i}}}{\sum E_{x i}} \times 100 \%
$$

Food supply balance as a state relates to sustainability of the food system and its ability to maintain equilibrium or perform its functions and tasks under external and internal breaches. In general, the concept "state" is rendered as a position that has something located; as a qualitative and quantitative description of the real and potential capacities of the system, their features and parameters in space and time; as the current state of affairs and relations that occur among them as well as a set of basic parameters and characteristics of an object, phenomenon or process at a certain period of time, and this concept is one of the key to characterize non-linear system and interactions that are changed by external and internal factors.

These approaches show that sustainability of the food system depends on the possibility of sustainable operation of each element of the system. This allows us to identify the structure of the system and the relations among its elements regarded as key characteristics that determine the possibility of achieving a balance of food supply as a state.

The specific features of food supply topic prevent application of this approach for the estimation of the degree of balance relations in the food system, as this interaction among the subjects of food supply system is not consistent. For instance, the first link in the process assumes that agricultural producers can sale their 
production themselves in some cases thus skipping two intermediary stages. The processing enterprises can skip retailing stage by means of opening own sales units. Exploring the relations by "pairs of subjects" will not show a reliable picture of the food supply balance, as in this case the degree of mutual impact of intra-system factors will not be considered.

As material flows from economically-oriented elements of food supply to sociallyoriented ones and financial flows in the reverse direction are seen as the links in the food system, the authors say about reasonable consideration of the food supply balance from the point of view of achieving the elements proportionality. In other words, the relations in the food system would be balanced when the parameters of material and financial flows among the food security actors are harmonized.

Interdependence of the food system structure and relations among its constituent elements is obvious, because in case of violation of the existing efficient relations, the actors of food supply system will have to change their parameters and patterns of operation and adapt to the new conditions, which change its structure. While ensuring the food supply balance as a state, we should harmonize the parameters of possible changes in material and financial flows among the food supply actors.

Due to this, the Pareto-optimality criterion in relation to the food supply balance as a state can be defined as "food supply as a state is efficient when the change in the dynamics of its elements does not reduce the degree of proportionality of material and financial flows among them, as well as does not violate the proportionality of its structure". Here, we assume that a non-equilibrium state is one in which the system is, or may be, subject to the change in its parameters at any time, when the food security actors will lose coherence.

In this case food supply balance as a state is reviewed as correspondence of proportionality of the food system structure and parity operation of system elements and relations among them. This correspondence is achieved by coordinating the parameters of possible changes in material and financial flows among its subjects. Thus, the main indicator characterizing the food supply balance as a state $(B s t)$ is a relation between the total value of food products produced (COST food), and total costs of the population on food (Spending) as in equation (3):

$$
B_{s t}=\frac{\sum C f_{i}}{\sum S p_{i}} \times 100 \%
$$

When assessing the food supply balance according to the mentioned elements, it would be wrong not to understand that application of the mechanism in order to find out the average value of $B p h, B p r$ and $B s t$ will result in losses of the qualitative component of the food balance and it would be impossible to consider the specific features of a certain area and economic and agricultural activities performed on this 
area. If one of the elements of assessment is broken, it could be supplemented (compensated) by other elements. In this case, the average parameter of balance varies within permissible levels.

The authors see an economic matrix as the most effective mechanism for food balance assessment. The matrix ranges the certain elements into the balanced parameters that vary within 95 - 105\% (Bph2; Bpr2; Bst2); lower than 95\% (Bph1; Bpr1; Bst1) and higher than 105\% (Bph3; Bpr3; Bst3) (Table 1).

Table 1. Matrix of food supply balance

\begin{tabular}{|l|l|l|}
\hline $\mathrm{Bph}_{1}$ & $\mathrm{Bpr}_{1}$ & $\mathrm{Bst}_{1}$ \\
\hline $\mathrm{Bph}_{2}$ & $\mathrm{Bpr}_{2}$ & $\mathrm{Bst}_{2}$ \\
\hline $\mathrm{Bph}_{3}$ & $\mathrm{Bpr}_{3}$ & $\mathrm{Bst}_{3}$ \\
\hline
\end{tabular}

The authors highlight that the range of the balanced state not equal to $100 \%$ is based on the fact that insignificant deviations of variables from their equilibrium values are self-correcting (Samuelson, 1953). The matrix is restricted by:

$$
\begin{gathered}
X_{1}\left(B p h_{1} ; B p h_{2} ; B p h_{3}\right) \\
X_{2}\left(B p r_{1} ; B p r_{2} ; B p r_{3}\right) \\
X_{3}\left(B s t_{1} ; \text { B } s_{2} ; B_{2} t_{3}\right)
\end{gathered}
$$

and it allows to analyze the parameters of food supply balance without losses of qualitative components and divide the parameters into 7 groups, where the I group reveals the lowest level of the balance and the VII group shows the highest degree of

\begin{tabular}{|c|c|c|}
\hline Group & $\begin{array}{l}\text { Parameters of } \\
\text { the balance }\end{array}$ & Characteristics \\
\hline I. & $\begin{array}{l}\mathrm{Bph}_{1} ; \mathrm{Bpr}_{1} ; \mathrm{Bst}_{1} \\
\mathrm{Bph}_{1} ; \mathrm{Bpr}_{1} ; \mathrm{Bst}_{2} \\
\mathrm{Bph}_{1} ; \mathrm{Bpr}_{1} ; \mathrm{Bst}_{3} \\
\mathrm{Bph}_{2} ; \mathrm{Bpr}_{1} ; \mathrm{Bst}_{1}\end{array}$ & $\begin{array}{l}\text { The authors observed imbalance in food supply that relates to } \\
\text { insufficient production of food products and low efficiency of } \\
\text { agribusiness. The costs of agricultural producers are not } \\
\text { covered by their income. Parameter Bst }{ }_{3} \text { observed with } \\
\text { parameter } B p h_{1} \text { would show not excess of self-sufficiency } \\
\text { with the food products but low demand in food products. }\end{array}$ \\
\hline II. & $\begin{array}{l}\mathrm{Bph}_{2} ; \mathrm{Bpr}_{1} ; \mathrm{Bst}_{2} \\
\mathrm{Bph}_{2} ; \mathrm{Bpr}_{1} ; \mathrm{Bst}_{3} \\
\mathrm{Bph}_{3} ; \mathrm{Bpr}_{1} ; \mathrm{Bst}_{1} \\
\end{array}$ & $\begin{array}{l}\text { Food standards are followed otherwise agribusiness is } \\
\text { inefficient, insufficient producing of food products and low } \\
\text { expenditures on food products are observed. }\end{array}$ \\
\hline III. & $\begin{array}{l}B p h_{1} ; \text { Bpr }_{2} ; \text { Bst }_{1} \\
\text { Bph }_{1} ; \text { Bpr }_{2} ; \text { Bst }_{2} \\
\text { Bph }_{1} ; \text { Bpr }_{3} ; \text { Bst }_{1} \\
B p h_{1} ; \text { Bpr }_{2} ; \text { Bst }_{3} \\
\text { Bph }_{1} ; \text { Bpr }_{3} ; \text { Bst }_{3}\end{array}$ & $\begin{array}{l}\text { Food products are not sufficient for full and complete human } \\
\text { diet; food products depend on importing products, but at the } \\
\text { same time, agricultural products are in demand and therefore } \\
\text { agricultural production is efficient. The factor that restricts } \\
\text { agricultural development is low competitiveness of } \\
\text { agricultural products. }\end{array}$ \\
\hline
\end{tabular}
the balance (Table 2).

Table 2. Groups of parameters of food supply balance and their characteristics 


\begin{tabular}{|c|c|c|}
\hline IV. & $\begin{array}{l}\mathrm{Bph}_{2} ; \mathrm{Bpr}_{2} ; \mathrm{Bst}_{1} \\
\mathrm{Bph}_{3} ; \mathrm{Bpr}_{1} ; \mathrm{Bst}_{2}\end{array}$ & $\begin{array}{l}\text { Food products produced are not sufficient for full and } \\
\text { sufficient human nutrition; there is a significant dependence } \\
\text { on imports, while the agricultural products are in demand; } \\
\text { agricultural production is efficient and profitable, but low } \\
\text { competitiveness of domestic agricultural products is seen as a } \\
\text { constraint in agricultural sector development. }\end{array}$ \\
\hline V. & $\begin{array}{l}\mathrm{Bph}_{3} ; \mathrm{Bpr}_{2} ; \mathrm{Bst}_{1} \\
\mathrm{Bph}_{3} ; \mathrm{Bpr}_{3} ; \mathrm{Bst}_{1}\end{array}$ & $\begin{array}{l}\text { Nutrition standards are endorsed and applied; there are export } \\
\text { capacities for certain types of food products, however, } \\
\text { agribusiness depends on state support; domestic demand can } \\
\text { be completely satisfied only for certain types of food } \\
\text { products; dependence on imports is observed. }\end{array}$ \\
\hline VI. & $\begin{array}{l}\mathrm{Bph}_{2} ; \mathrm{Bpr}_{2} ; \mathrm{Bst}_{2} \\
\mathrm{Bph}_{2} ; \mathrm{Bpr}_{2} ; \mathrm{Bst}_{3} \\
\mathrm{Bph}_{2} ; \mathrm{Bpr}_{3} ; \mathrm{Bst}_{3}\end{array}$ & $\begin{array}{l}\text { Nutrition standards are endorsed and applied on almost all } \\
\text { types of food products, some of them have high export } \\
\text { capacities, agricultural production is efficient, however } \\
\text { domestic agribusiness cannot fully meet the human needs; the } \\
\text { significant part of the people expenditures is spent on } \\
\text { purchasing imported products. }\end{array}$ \\
\hline VII. & $\begin{array}{l}\mathrm{Bph}_{3} ; \mathrm{Bpr}_{2} ; \mathrm{Bst}_{2} \\
\mathrm{Bph}_{3} ; \mathrm{Bpr}_{2} ; \mathrm{Bst}_{3} \\
\mathrm{Bph}_{3} ; \mathrm{Bpr}_{3} ; \mathrm{Bst}_{3} \\
\end{array}$ & $\begin{array}{l}\text { The food supply is balanced, agribusiness sector is efficient } \\
\text { and there are export capacities for certain types of agricultural } \\
\text { products. }\end{array}$ \\
\hline
\end{tabular}

The specific features of the food sector define the levels of $B p h_{l} ; B p r_{l} ; B s t_{1}$, i.e., differentiating the degree of imbalance in food supply. The authors make a case it is rather logical as this differentiation facilitates the assessment of the real situation in a certain area of agribusiness and to take efficient decisions, for instance, to increase the production of a particular type of food, or to support a particular sector of agribusiness. Table 3 shows the degree of imbalance in food supply.

Table 3. Degree of imbalance in food supply

\begin{tabular}{|l|l|l|}
\hline Group & \% of balance & Degree of imbalance \\
\hline 1. & $76-95 \%$ & Permissible (Low) \\
\hline 2. & $51-75 \%$ & Middle \\
\hline 3. & $26-50 \%$ & High \\
\hline 4. & $0-25 \%$ & Crucial \\
\hline
\end{tabular}

\section{Results}

Due to this, the authors assessed the degree of food supply balance in some countries of EU and in the Russia as shown in Table 4:

Table 4. Degree of food supply balance in some countries of EU and in the Russia

\begin{tabular}{|l|l|l|l|l|l|l|l|}
\hline \multirow{2}{*}{ Years } & \multicolumn{1}{|l}{ Bph } & \multirow{2}{*}{ Bpr } & \multirow{2}{*}{ Bst } \\
\cline { 2 - 8 } & Meat & Milk & Bread & Fruits & Vegetables & \multirow{2}{l|}{} \\
\hline The Great Britain \\
\hline 2015 & 346,5 & 100,9 & - & 6,5 & 43,4 & 201,7 & 26,8 \\
\hline 2016 & 343,0 & 96,8 & - & 5,9 & 40,4 & 198,8 & 29,0 \\
\hline
\end{tabular}




\begin{tabular}{|l|l|l|l|l|l|l|l|}
\hline 2017 & 347,3 & 99,2 & - & 6,2 & 42,9 & 216,6 & 27,8 \\
\hline France \\
\hline 2015 & 177,2 & 163,9 & - & 42,4 & 83,1 & 207,2 & 36,0 \\
\hline 2016 & 179,2 & 159,2 & - & 40,1 & 85,0 & 194,2 & 35,7 \\
\hline 2017 & 174,1 & 158,2 & - & 38,1 & 86,3 & 205,8 & 38,1 \\
\hline Czech Republic \\
\hline 2015 & 55,2 & 66,5 & 364,4 & 22,9 & 20,9 & 237,7 & 23,4 \\
\hline 2016 & 55,3 & 74,8 & 376,3 & 18,2 & 25,8 & 255,2 & 20,5 \\
\hline 2017 & 53,9 & - & 324,7 & 14,8 & 27,2 & 253,0 & 21,9 \\
\hline Latvia & \multicolumn{7}{|l|}{} \\
\hline 2015 & 83,5 & 91,7 & 965,5 & 16,3 & 61,4 & 231,3 & 39,1 \\
\hline 2016 & 92,1 & 93,5 & 892,7 & 19,6 & 63,2 & 219,7 & 38,6 \\
\hline 2017 & 101,7 & 96,1 & 934,7 & 15,8 & 50,6 & 238,2 & 37,7 \\
\hline Russia
\end{tabular}

To prepare Table 4 the following data were used:

1. Cost indicators of EU countries were assessed in euros, while those of Russia were assessed in rubles. The assessment of the degree of food supply balance as a phenomenon $(B p h)$ is conducted for the most important products included in the healthy diet as meat, milk, bread, fruits and vegetables.

2. Considering that the food basket in the UK, France and the Czech Republic is not of a regulatory basis, the data of the Federal State Statistics Service of Russia serve as food consumption standards on current food consumption in these countries for a certain year. The data of 2015 were used as a basis for meat, milk, vegetables and bread consumption in Czech Republic; data on fruit consumption of 2014 were used for Czech Republic as well. The data of 2013 were used as a basis for meat, milk and vegetables consumption in the Great Britain and France; the data of 2011 for fruit consumption were used.

3. The value of agricultural products produced in the EU countries is estimated according to «Agricultural Gods Output».

4.

EU

Food

Costs.

5. Meat production in the EU countries is estimated according to «Bovine meat»+ «Pigmeat» + «Meat of sheep and goats» + «Poultry meat».

6. Milk production in the EU countries is estimated according to «Farm milk products delivered to dairies».

7. Bread production in the EU countries is estimated according to «Wheat and spelt», the calculation is conducted on flour with $75 \%$ extraction milling.

8. Fruit production in the EU countries is estimated according to «Fruits, berries and nuts (excluding citrus fruits, grapes and strawberries)» $+\langle$ Oranges $\rangle+\langle$ Lemons and acid limes» + «Grapes for table use».

9. Vegetable production in the EU countries is estimated according to «Fresh vegetables (including melons) and strawberries». 
10. Statistics on bread consumption in the UK and France and on milk production in the Czech Republic for 2017 are not available, so was impossible to calculate the corresponding coefficients.

11. In Latvia the bread consumption rate was assessed for cereal-based products, including pasta.

12. In Russia assessment of the food consumption rate was carried out for the ablebodied population.

The analysis shows that Great Britain belongs to the V group of balance indicators, but climate conditions are not suitable for complete satisfying human needs in fruits and vegetables; the degree of imbalance in providing fruits and vegetables is estimated as medium and high respectively. Significant export capacities for meat and meat products, which to some extent is the driving force of national agribusiness, supports high efficiency of agricultural production. The high degree of food imbalance resulted from the fact that in 2017 the UK population spent 97.2 billion euros on food products, while the national agricultural sector produced food products on 27 billion euros only.

The food supply of France belongs to group V, but it is more balanced than in the UK. The authors observed high export capacities for meat, meat products and milk. Favorable climate conditions contribute to the French agribusiness and make it possible to satisfy human needs in fruits (85\%) and vegetables (40\%). When the indicators of the food supply balance as a process are equal, the French agribusiness produces food products in 2.5 times more than in the UK, which results in $10 \%$ increase of $B s t$ parameter.

The food supply of the Czech Republic is assessed according to the III group of equilibrium indicators and it is characterized by prior development of grain crops production. The authors observed significant imbalance in other food products and import dependence. The Bst indicator is the lowest among the explored countries.

The balance in food supply in Latvia differs significantly from other countries in the fact that the growth of $B p h$ indicator on meat and milk does not relate to development of livestock industry and increase in livestock production, but it relates to reduction of the country's population. The population of Latvia decreased from 1.986 to 1.950 million people $(1.8 \%)$ from 2015 to 2017 . This allowed the national agribusiness to almost completely eliminate the dependence on import of basic food products, except fruits and vegetables. However, they are 1.5-2 times higher than those in the United Kingdom, and Bst indicators are estimated at the level of France. The total level of food balance in Latvia can be assessed according to parameters of group IV.

Considering the parameters of all countries represented in the Table, in Russia the food supply balance index as a state is at the level of Bst 3 ; coupled with high efficiency of agricultural production $\left(\mathrm{Bpr}_{3}\right)$ and balanced meat and bread indicators, 
the authors conclude that Russia has reached the VI group of equilibrium, or it is very close to it. This idea is supported by the fact that there is no crucial level of Bph imbalance in any of the explored food products. The analysis indicates that the country has capacities to increase domestic production of milk and vegetables without profound structural changes for satisfying human needs in fruits.

\section{Conclusion, Limitations and Avenues for Further Research}

The approach contributes to reconsideration of the problem of food supply balance and can become the mechanism for precise elaboration of efficient decisions in food security sector.

For instance, the countries, where food supply balance can be characterized from the views of I and III group indicators, they should facilitate and enhance domestic production of food products. When we consider group II, then the main problem is seen in the rise in profitability of agribusiness enterprises. Groups IV and V require more active import substitution and expansion of the domestic food products range. This will keep and save finance in the country therefore, it can support domestic agricultural production.

The methodology and methods of food supply balance estimation proposed by the authors can become the fundamental ones for facilitating human nutrition.

\section{References:}

Brykin, I.A. 2011. The Economic Mechanism for the Sustainable Development of the Food Market in the Region. Bulletin of the Oryol State Agrarian University, 31(4), 89-91.

Cassman, K.G., Harwood, R.R. 1995. The nature of agricultural systems - food security and environmental balance. Food Policy, 20(5), 439-454. doi: 10.1016/03069192(95)00037-f.

Chen, Y.F., Nie, F.Y. 2016. Analysis of China's Food Supply and Demand Balance and Food Security. In Kiminami, L., Nakamura, T. (eds.), Food Security and Industrial Clustering in Northeast Asia: New Frontiers in Regional Science-Asian Perspectives, 6, 47-59. Springer. doi: 10.1007/978-4-431-55282-6_4.

Clapp, J. 2012. Hunger in the Balance: The New Politics of International Food Aid. Cornell University Press, New York.

Crute, I. 2012. Balancing the Environmental Consequences of Agriculture with the Need for Food Security. In Harrison, R.M., Hester, R.E. (eds.), The environmental impact of modern agriculture: Issues in Environmental Science and Technology Series, 34, 129-149. Royal Society of Chemistry, Cambridge. doi: 10.1039/978184973497400129.

Fraser, I., Lansink, A.O. 2017. Special issue: Plenary papers of the XVth EAAE Congress, Parma, Towards Sustainable Agri-Food Systems: Balancing between Markets and Society. European Review of Agricultural Economics, 44(4), 539-540. doi: 10.1093/erae/jbx021.

Hammer, M. 2004. Deep change: How operational innovation can transform your company. Harvard Business Review, 82(4), 84-93. 
Hopkins, R.F. 2009. Responding to the 2008 "Food Crisis" Lessons from the Evolution of the Food Aid Regime. In Clapp, J., Cohen, M.J, (eds.), Global Food Crisis: Governance Challenges and Opportunities, 79-93. Wilfrid Laurel Univ Press, Waterloo.

Hossain, M. 2007. Technological Progress for Sustaining Food-population Balance: Achievement and Challenges. Agricultural Economics, 37, 161-172. doi: 10.1111/j.1574-0862.2007.00242.x.

Kostusenko, I.I. 2009. Self-sufficiency of the Regions of the Russian Federation with Dairy and Meat Products. Agrarian Bulletin of the Urals, 57(3), 18-22.

Nadezhdina, S.D., Peshkova, M.N. 2014. Methods for Assessing the Balance of the Regional Food Market. Bulletin of the Novosibirsk State Agrarian University, 32(3), 120-125.

Rask, K.J., Rask, N. 2011. Economic Development and Food Production-Consumption Balance: A Growing Global Challenge. Food Policy, 36(2), 186-196. doi: 10.1016/j.foodpol.2010.11.015.

Repin, V.V., Eliferov, V.G. 2008. Process approach to management: modeling business processes. Practical management (6th edition). Standards and quality, Moscow.

Sali, G., Monaco, F., Mazzocchi, C., Corsi, S. 2016. Exploring land use scenarios in metropolitan areas: food balance in a local agricultural system by using a multiobjective optimization model. In Menghini, S., Pfoestl, E., Marinelli, A. (eds.), Agriculture and Agricultural Science Procedia: Florence «Sustainability of WellBeing International Forum». Food for Sustainability and Not Just Food, Florenceswif2015, 8, 211-221. Elsevier. doi: 10.1016/j.aaspro.2016.02.095.

Samuelson, P.A. 1953. Prices of Factors and Goods in General Equilibrium. Review of Economic Studies, 21(1), 1-20.

Shapkina, L.N. 2011. Balanced Nutrition of the Population as a Factor in Ensuring Food Security of the Population. Problems of economics, 5, 50-52.

Shibajkin, A.V. 2009. Trends in the Development of the Food Market in Russia. Bulletin of the Saratov State Socio-Economic University, 27(3), 145-149.

Silaeva, L.P., Kuz'menkova, V.D., Shiryaeva, N.V. 2009. Production and Consumption of Major Agricultural Products, Raw Materials and Food. International Agricultural Journal, 3, 34-37.

Sulejmanov, M.V., Nasrullaeva T.D. 2012. On the Balance of Development of the Regional Food Market of Dagestan. Economic structuring issues, 1, 81-84.

Umali-Deininger, D.L., Deininger, K.W. 2001. Towards Greater Food Security for India's Poor: Balancing Government Intervention and Private Competition. Agricultural Economics, 25(2-3), 321-335. doi: 10.1111/j.1574-0862.2001.tb00212.x.

Usenko, L.N. 2006. The Aim is Balanced Nutrition of the Population. Economics of Agriculture of Russia, 9, 6-7.

Vorob'ev, N.N. 2005. Balancing the Demand and Supply of Food Products in the Stavropol Territory. AIC: Economics, Management, 10, 27-31.

Vorotnikov, I., Sukhanova, I., Tretyak, L., Baskakov, S. 2017. A Logistics Model of Sustainable Food Supply of the Region. Economic Annals-XXI, 164(3-4), 94-98. doi: 10.21003/ea.V164-21.

\section{Internet sources:}

http://www.gks.ru/wps/wcm/connect/rosstat_main/rosstat/ru/statistics/publications/catalog/d oc 1139821848594 .

http://appsso.eurostat.ec.europa.eu/nui/submitViewTableAction.do. 
Food Balancing Assessment: A Three-Way Approach

416

https://ec.europa.eu/eurostat/tgm/table.do?tab=table\&init $=1 \&$ plugin $=1 \& p \operatorname{code}=t e c 00134 \&$ language $=e n$.

http://appsso.eurostat.ec.europa.eu/nui/show.do?dataset=apro mt_pann.

http://appsso.eurostat.ec.europa.eu/nui/show.do?dataset=apro $m$ m farm\&lang=en.

http://appsso.eurostat.ec.europa.eu/nui/submitViewTableAction.do.

http://appsso.eurostat.ec.europa.eu/nui/submitViewTableAction.do.

http://appsso.eurostat.ec.europa.eu/nui/submitViewTableAction.do. 